\title{
Efficacy of Hyperbaric Oxygen Therapy on Second Degree of Burn Wound of Forearm
}

\author{
Wafaa Borhan*, Maher El Kebelawy*, and AshrafEI Sebaie**. \\ * Faculty of Physical Therapy, Cairo University. \\ **Department of surgery, Faculty of Medicine, Cairo University.
}

\begin{abstract}
The purpose of the current study was to investigate the effects of hyperbaric oxygen therapy on second degree bum wound healing of the forearm. Thirty patients included in this study (eighteen males and twelve females). All were suffering from deep second degree flame bum in the forearm, their age ranged from thirty to forty years. The total burned surface area was $15-25 \%$. They were randomly classified into two equal groups. The first group (15 patients) treated by the Hyperbaric Oxygen Therapy (HBOT) plus traditional conservative treatment, while the second group, sea level air-breathing equivelent control group 15 patients received placebo HBOT plus traditional conservative treatment. Assessment of the wound surface area was performed before starting the study and after 15 days by using the metric graph paper and computerized planimetry linked to summagraphic digitizer system .Procedure started $48 \mathrm{hrs}$ post bum. The program was conducted at Naser Institute; oxygen was supplied $100 \% \mathrm{O}_{2}$ at 2.4 Atmospheric Absolute (ATA) for two hours during each treatment period. Treatment was given on four consecutive days each week for two weeks. The results of this study showed significant decrease of the wound surface area in the treatment group (43.6\%) than the control group $(18.91 \%)$, reflecting efficacy of HBOT in healing process. It was concluded that, HBOT seems effective in accelerating the healing rate and shortening of hospitalization time

on second degree bum wound of the forearm .
\end{abstract}

Key Words: Hyperbaric Oxygen Therapy, Bum, wound.

\section{Introduction}

Thermal injury primarily results in the destruction of skin and secondarily involves functions of the musculoskeletal system. The degree of musculoskeletal impairment is determined by the depth and extent of the bum injury (Martyn ,1990).

The healing of wound is the main problem for the physical therapist who deals with many functional problems of burned patient. The ultimate goal of it is to allow wound to close as rapidly as possible (Richard and Staley,1994).

Hyperbaric oxygen therapy is the treatment in which a patient breathes $100 \%$ oxygen intermittently under a pressure of greater than sea level or one atmospheric pressure. This treatment can be carried out in one of two ways. Mono place chambers are single person chambers that are pressured with oxygen. Dual or multi place chambers arc designed to hold 2 or more patients, up to as many as 36 . Both types may be pressured with air while patients breathe oxygen via an oxygen mask, hood system, for times that typically extend 4-6 hours during which the patient breathes $100 \%$ oxygen (Delaney and Montgomery, 2001).

Because of toxic side effects from the systemic absorption of oxygen, which include pulmonary and eNS toxic reactions, localized therapy has popularity, Heng and others used disposable polyethylene bags, which has the advantages of being simple, and less likely to cause cross- infection (Heng et al,1984).

Hyperbaric Oxygen Therapy (HEOT) is indicated for decompression sickness, air 
embolism, carbon monoxide poisoning, acute traumatic ischemia (crush injuries that deprive tissues of oxygen), and bacterial invasion of a necrotic wound (in which tissue has died). HBOT may also stimulate re-growth of blood vessels in damaged tissue adjacent to areas treated by radiation therapy and may promote bone formation in cases of osteomyelitis that have not responded to other treatments. Hyperbaric oxygen therapy also shows promise for treating a variety of problem of wounds, but randomized, prospective studies are lacking (Grim and Gottlieb,1999).

On the other hand wound healing is a complex process and involves the interaction of many cell types and biochemical mediators. Hyperbaric oxygen therapy increases tissue oxygenation and amplifies the oxygen gradient along the periphery of ischemic wounds. This oxygen gradient has been demonstrated to be an important stimulus to angiogenesis and wound healing (Knighton et al,2000).

Furthermore hyperbaric oxygen therapy works by elevating the plasma oxygen level. It also enhance fibroblasts synthesis and modifies collagen. Both these activities require relatively high partial pressures of oxygen. Increasing okygen tensions also has a direct and toxic effect on anaerobes; therefore hyperbaric oxygen therapy has a special role in treating wound infections (Kalani et al,2002).

Several investigations showed that hyperbaric oxygen therapy in conjunction with aggressive multidisciplinary therapeutic tools is effective in decreasing major amputations in diabetic patients with severe resistant ischemic wounds (Leach et $a l, 1998)$, and (Faglia et al,1996).

It was reported that, during HBOT, barometric pressures are usually limited to 3 absolute temperature air (A $\mathrm{T} A$ ) or lower. The oxygen content of inspired air in the chamber is typically $95 \%$ to $100 \%$. The combination of increased pressure (3 AT A) and increased oxygen concentration (100\%) dissolves enough oxygen in the plasma alone to sustain life in a resting state. Under hyperbaric ccnditions, oxygen content in the plasma is increased from 0.3 to $6.6 \mathrm{~mL}$ per $100 \mathrm{~mL}$ of blood with no change in oxygen transport via hemoglobin. HBOT at 3.0 ATA, increases oxygen delivery to the tissues from 20.0 to $26.7 \mathrm{~mL}$ of oxygen per $100 \mathrm{~mL}$ of blood (Delaney and Montgomery,2001) and (De Martino et al,1996).

The present study is an attempt to investigate the effect of HBOT on second degree bum wound of forearm. The results of current study might help physicians and physical therapists to introduce HBOT as a new modality for burned patient aiming to enhance the process of healing.

\section{Materials And Methods Subjects}

Thirty patients (eighteen male and twelve females) suffering from post- bum wound in the forearm after thermal second degree of bum. They were ranging in age from thirty to forty years old. Mean of age

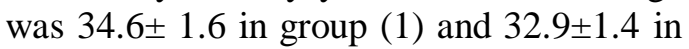
group (2). Mean of height was 163.6 \pm 0.9 in group (1) and 160.66 0045 in group (2). Mean of weight was $66.3 \pm 1.5$ in group (1) and $64.5 \pm l A$ in group (2). Patients were selected from the department of bum in EIMataryia teaching hospital. They were classified into two equal groups. They received traditional medical treatment plus $100 \% \mathrm{O}_{2}$ at $204 \mathrm{~A}$ TA for the study group and also traditional medical 'treatment plus $8.75 \% \mathrm{O}_{2}$ at 2.4 ATA for control group, the treatment was applied at Naser Institute for research and treatment. It was given on four consecutive days each week for two weeks, Each session was continued for two hours during each treatment period. The design of the study was pre test, post test control group. The subjects included in the study were non diabetic or hypertensive and free from vascular disorders that might affect healing.

\section{Instrumentation}

A) Instrumentation for evaluation:

The metric graph paper and computerized planimetrylinked to summagraphic digitizer system was used in current study (De Martino et al,1996).

B) Therapeutic equipments:

Multiplace hyperbaric chamber was used for the treatment procedures. Figure (1). 


\section{Wafaa Borhan et al}

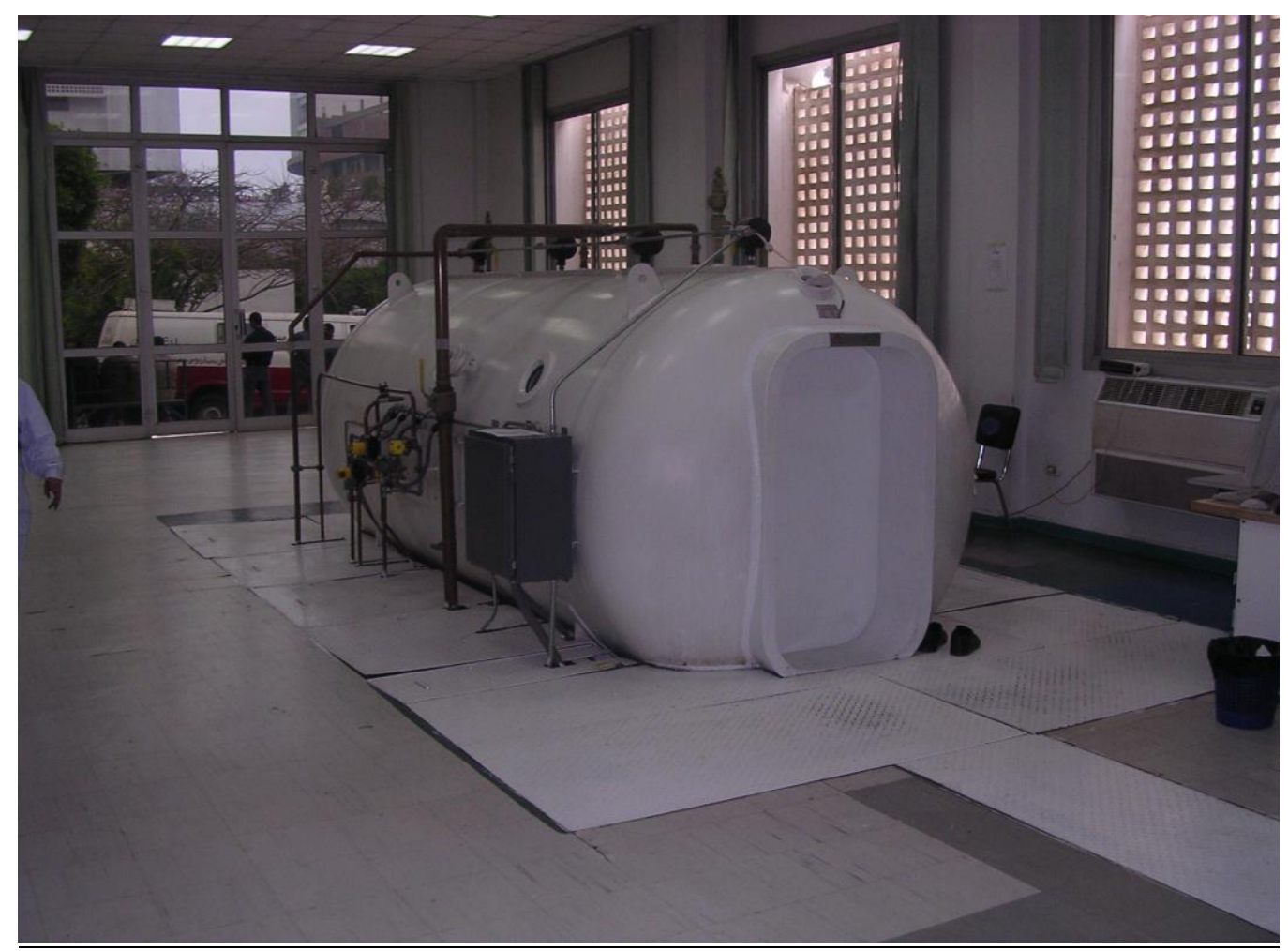

Figure (1) The Hyperbaric chamber.

\section{Procedure}

A) Evaluation Procedure and Method of Determinin2: Wound Surface Area:

Each wound size was measured before starting the treatment and after fifteen days of treatment by tracing its outline on transparent tape. The area of the wound was then measured through computerized planimetry on a computer linked to summagraphic digitizer systems (De Martino et al,1996).

\section{B)Treatment procedures:}

Group (1), every patient was relaxed in sitting position. Treatment pressure 2.4ATA was reached by pumping air into the chamber over fiv $\sim$ minutes period. Once at treatment depth, either $100 \%$ oxygen or the 8.75 oxygen mixture through a tightfitting aviators mask or a clear vinyl hood for three thirty minutes periods were separated by ten minutes air breaks, during which subjects removed their masks or hoods in order to minimize the potential for oxygen toxicity because of increasing nitrogen on10ading by the control group and the associated risk of developing decompression sickness during chamber ascent

Group (2), this group followed the same procedures as the study group but at 8.75 oxygen ATA instead of $100 \%$ oxygen.

\section{RESULTS}

In the present study the effect of hyperbaric oxygen therapy on the healing process of deep second degree bum wound after thermal bum was investigated by calculating the wound surface area. Mean of age showed no significant differe!1ces between both groups. Mean of height showed no significant differences between both groups. Mean of weight showed no significant differences between both groups.

On the other hand, as shown in the table and figure (2) below, the mean value of the wound surface area before starting the treatment was $9.25 \mathrm{~cm} \pm 1.3$ for the 
control group. While it was $8.36 \mathrm{~cm} \pm 0.8$ for the treatment group with a non significant difference $(p>0.05)$. Furthermore after treatment waslOA \pm 3.3 for the control group with percentage of change $18.91 \%$. While it was $4.71 \pm 0.45$ for the treatment group reflecting a significcmt difference $(\mathrm{p}<0.05)$ with percentage of change 43.61 $\%$

Wound surface area in square millimeters (sq $\mathrm{mm}$ ). For the patients before starting the treatment and after 15 days.

\begin{tabular}{|c|c|c|c|c|c|c|c|c|}
\hline \multirow{2}{*}{ Statistics } & \multicolumn{2}{|c|}{ Pre-treatment } & \multicolumn{2}{c|}{ Post-treatment } & \multicolumn{3}{c|}{ Percentage of healing } \\
\cline { 2 - 10 } & Control & Treatment & Control & Treatment & \multicolumn{2}{c|}{ Control } & \multicolumn{2}{c|}{ Treatment } \\
\hline Mean & 9.25 & 8.36 & 7.5 & 4.71 & Pre & Post & Pre & Post \\
\hline \pm SD & 1.3 & 0.8 & 3.31 & 0.45 & 9.25 & 7.5 & 8.36 & 4.71 \\
\hline "p" value & \multicolumn{2}{|c|}{0.087} & \multicolumn{2}{c|}{0.03} & 1.3 & 3.31 & 0.8 & 0.45 \\
\hline $\begin{array}{c}\text { Level of } \\
\text { significance }\end{array}$ & \multicolumn{2}{|c|}{ N.S } & \multicolumn{2}{c|}{ S } & \multicolumn{2}{c|}{$18.91 \%$} & \multicolumn{2}{c|}{$43.6 \%$} \\
\hline
\end{tabular}

SD: Standard Deviation $\quad$ S: Significant N.S: Non Significant

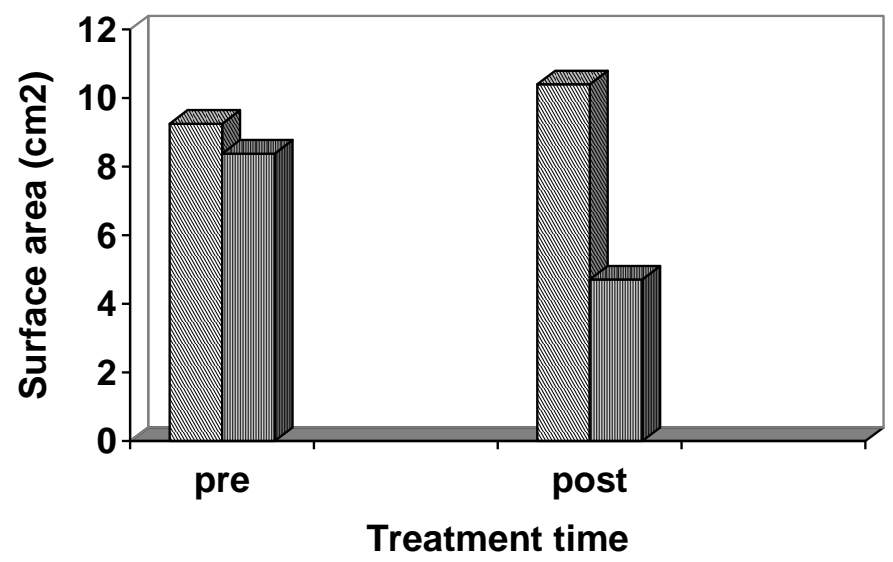

Figure (2): Mean values of the wound surface area for both groups

\section{Discussion}

The apparent faster healing observed at the end of treatment in the current study could be explained by the kinetics of the healing process, which begins slowly and then increases. On the other hand HBOT has a significant direct and indirect effect on the infection. Furthermore HBOT has a direct antibacterial effect on the anaerobic microorganisms. Also ill current study, it was observed that, there was a significant improvement after 15 days of treatment of the wound surface area (Kloth and Feeder, 1988).

It was reported that, hyperoxia may potentiate antimicrobial therapy. Studies on dog skin flap model demonstrated that local tissue resistance to infection is directly proportional to the level of oxygen tension found in tissue. Also the area of necrosis was inversely proportional to the oxygen concentration of the breathing mixture (Hamilton,1999).

According to severed investigators, hyperbaric oxygen therapy promotes wound healing by directly enhancing fibroblast replication, collagen synthesis and neovascularization. Providing oxygen at the cellular level also increases leukocyte bactericidal activity and has a direct lethal effect on anaerobic organisms (Bonomo et al, 2000).

Therefore, elevation of $\mathrm{O}_{2}$ tension in hypoxic wound ulcers enhances neutrophil oxidative killing of bacteria and stimulates fibroblast proliferation, collagen production, neovascularization, and epithe- 


\section{Wafaa Borhan et al}

lialization. In addition, $\mathrm{O}_{2}$ is directly toxic to anaerobic organisms. The bacterial activity is inversely proportional to tissue oxygen supply. Furthermore, elevation of wound oxygen tension may be as effective as antibiotic administration (Bakker,2000).

In normoxic environments, tissue hypoxia may develop. However, this is not the case with HBOT. The decrease in regional blood flow is more than compensated for by the increased plasma oxygen that reaches the tissue. The net effect is, decreased tissue inflammation without hypoxia this was explained through a mechanism by which hyperbaric oxygen therapy is believed to improve crush injuries, thermal bums, and compartment syndrome (Hunt and Aslam,2004).

As regards neovascularization and epithelialization, high tissue oxygen concentrations accelerate the development of new blood vessels. This can be induced in both acute and chronic injuries. Regenerating epithelial cells also function more effectively in a high oxygen environment. These effects have proven effective in treating tissue ulcers and skin grafts (Cianci,2004).

On the other hand stimulation of fibroblasts and osteoclasts, in a hypoxic milieu, fibroblasts are unable to synthesize collagen, and osteoclasts are unable to lay down new bone (Marino,1991).

Collagen deposition, wound strength and the rate of wound healing are affected by the amount of available oxfgen. Ischemic areas of wounds benefit most from the increased delivery of oxygen (Bouachour, et al, 1996) and (Staples et al ,1999).

It was noticed that immune response, when tissue oxygen tensions fall below 30 $\mathrm{mm} \mathrm{Hg}$, susceptibility to infection and ischemia are compromised (LaVan and Hunt,1990). Also Studies have shown that the local tissue resistance to infection is directly related to the level of oxygen found in the tissue (Davis and Hunt,1988).

Hunt and Aslam, 2004 and Knighton et al.,2000 have demonstrated that oxygen adds to the effectiveness of antibiotics; the greater the concentration of oxygen, the more pronounced the effect
(Bakker,2000), (Hunt and Aslam,2004).and (Cianci,2004).

Recently Cianci, 2004 reported that the white blood cells that fight the infection in the ulcer use 20 times more oxygen when they are killing bacteria (Cianci,2004).Also the more oxygen the more efficiently the repair of the connective tissues. New capillaries mean that more blood gets to the site of the ulcer, which spreads healing. High oxygen levels also make red blood cells more flexible so they can get through the twists and turns of the capillaries and get to where are needed.

In the present study beside the previous explanation which supports the observed results in group (1), the acceleration of healing in study group might be attributed to vasoconstriction, high tissue oxygen concentrations that cause blood vessels to constrict, which can lead to a $20 \%$ decrease in regional blood flow (Weiss, 1994) and (Hammarlund, 1995).

It was concluded that, HBOT seems effective in accelerating the healing rate and shortening hospitalization time on second degree of bum wound of forearm.

\section{References}

1. Bakker DJ (2000): Hyperbaric oxygen therapy and the diabetic foot. Diabete Metab Res Rev; 16: 55-58.

2. Bonomo SR, Davidson D, Tyrone jW (2000): Enhancement of wound healing by hyperbaric oxygen and transforming growth factor in a new chronic wound model in aged rabbits. Arch Surg; 135: 1148-1153.

3. Bouachour G, Cronier P, Gouello JP (1996): Hyperbaric oxygen therapy in the management of crush injuries: A randomized double-blind placebo controlled clinical trial. J Trauma; 41: 333-339.

4. Cianci P (2004): Advances in the treatment of the diabetic foot: Is there a role for adjunctive hyperbaric oxygen therapy? Wound Repair Regen; 12: 2-10.

5. Davis 1C and Hunt TK (1988): Problem Wounds: The Role of Oxygen. New York City, Elsevier, pp 5-30.

6. De Martino G, Luchetti M, De Rosa RC (1996): Toxic Effects of Oxygen In Handbook of Hyperbaric Medicine. NY: Springer-Verlag: 59-74. 
7. Delaney Sand Montgomery DL (2001): How can hyperbaric oxygen therapy contribute to treatment? The Physician and Sports Medicine; 29: 616-625.

8. Faglia E, Favales F, Aldeghi A (1996): Adjunctive systemic hyperbaric oxygen therapy in treatment of sever prevalently ischemic diabetic foot ulcer. Diabetes Care; 19: 1338-1343.

9. Grim P S, Gottlieb (1999): Hyperbaric Oxygen. JAMA; 25(263): pp.221.

10. Hamilton MR (1999): Fourth consensus conference of the European committee on hyperbaric medicine Diabetes Nutr Metab; 12: 47

11. Hammarlund $C$ (1995): The physiologic Effects of hyperbaric oxygenation, In Whelan HT, Kindwall EP (eds): Hyperbaric Medicine Practice, ed 2. Flagstaff, Arizona, Best Pub Co, pp 37-68.

12. Heng MC, Pilgrim JP and Beck FW (1984): Asimplified Hyperbaric Oxygen Technique for leg ulcers> Arch Dermato(120): 640-645.

13. Hunt TK and Aslam RS (2004): oxygen and Wounds .Under Sea Hyperb Med ;31: 147-153.

14. Kalani M, Jomeskog G, Naderi N (2002): Hyperbaric oxygen therapy in treatment of diabetic foot ulcers. Long-term follow-up. J Diabetic Complication 16: 153-158.
15. Kloth L.C., and Feeder, J.A.,(1988): Acceleration of Wound Healing with High Voltage Monophasic Pulsed Current" Phys Ther:68 (4): 503-508.

16. Knighton D, Silver I, Hunt TK (2000): Hyperbaric air. ADF Health 81 :66-67.

17. LaVan FB and Hunt TK (1990): Oxygen and wound healing. Clin Plast Surg 17(3): 463-472.

18. Leach RM, Rees $\mathbf{P} \mathbf{J}$, Wilmshurst $\mathbf{P}$ (1998): ABC of Hyperbaric oxygen therapy. BMJ; 317: 1140-1143.

19. Marino PL (1991): Oxygen transport, in Marino PL (Ed): The ICD Book, Ed 1. Philadelphia, Lea \& Febiger, pp 14-24.

20. Martyn JA(1990): "Acute Management of Bumed Patients" W.B Saunders Company PhiladelPhia, pp 288-290

21. Richard R.L, and Staley,M.J.,(1994): Bum Care Rehabilitation, Pathologic manifestations of bum injury. Eds 1, F.A. Davis Company, Philadelphia, pp: 30-47

22. Staples JR, Clement DB, Taunton JE (1999): Effects of hyperbaric oxygen on a human model of injury. Am J Sports Med; 27(5): 600-605.

23. Weiss EL (1994): Connective tissue in wound healing, In McCulloch JM, Kloth LC, Feeder JA (eds): Wound Healing: Alternatives in Management, ed 2. Philadelphia, FA Davis Co, pp 16-31. 


\section{فاعلية العلاج بالأكسجين المفرط الضغط فى جرح حرق الارجة الثانية للساعد}

\section{وفاء برهان*، ماهر القبلاوى**، و أشرف السباعى**.}

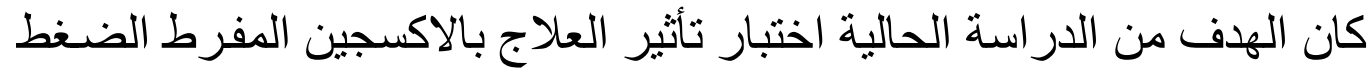

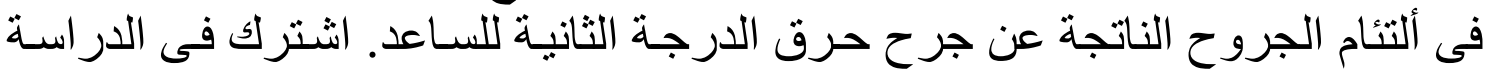

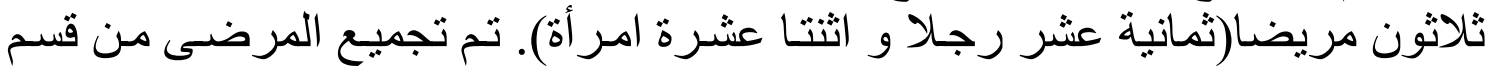

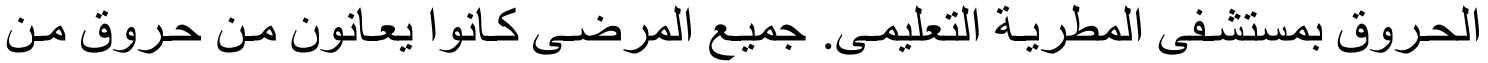

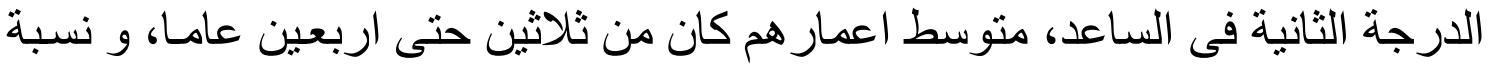

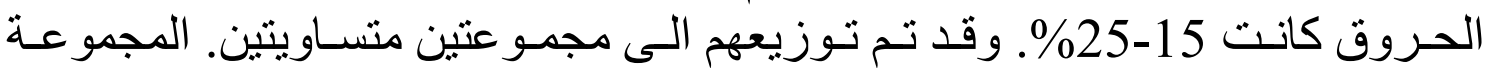

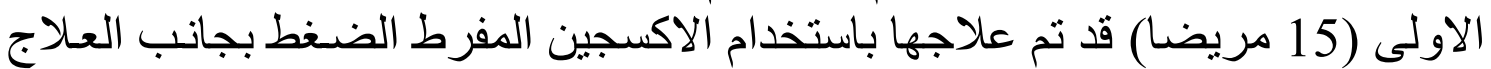

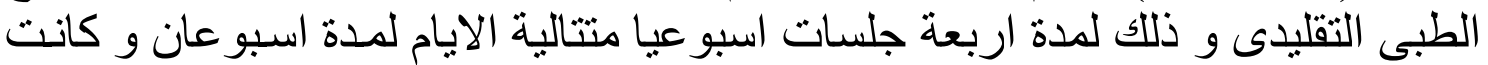

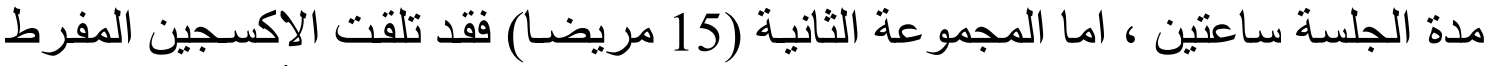

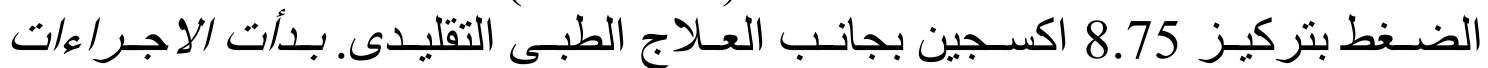

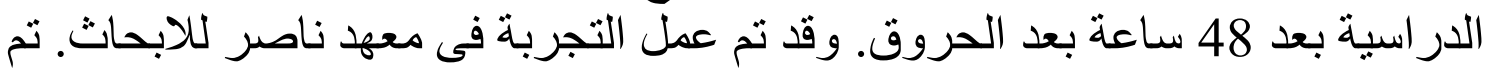

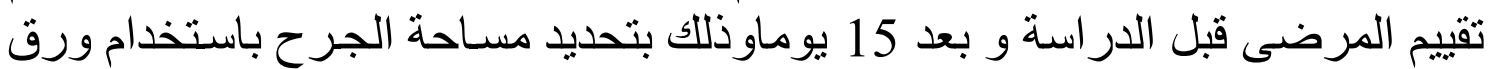

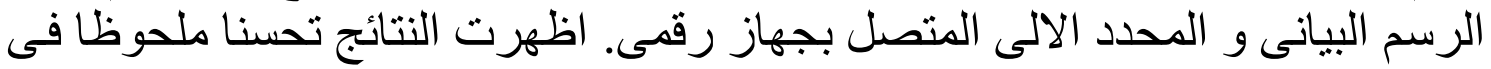

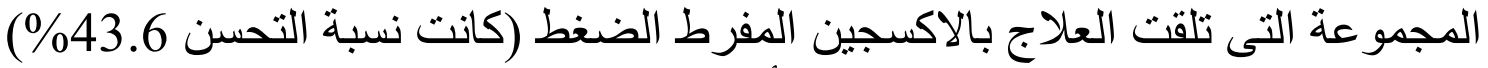

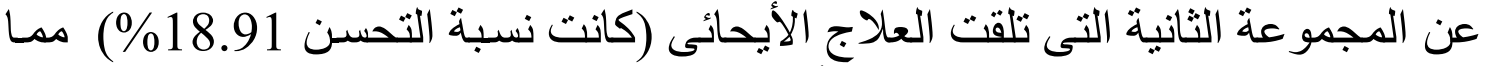

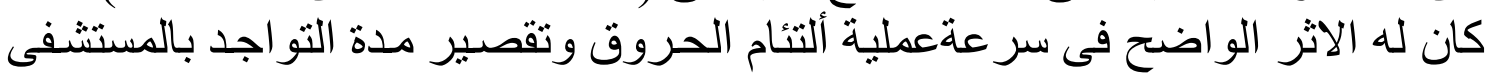
و ذلك لمرضى جرح حرق الأرجة فئ الثانية فى الساعد. 